\title{
Annotations
}

\section{Psychological management of overdose in young people}

More and more children take overdoses every year. ${ }^{1}$ Deliberate self poisoning is a very common medical emergency in the 12 to 18 years age group. ${ }^{2}$ Suicide is also becoming more prevalent among teenagers ${ }^{3}$ and is now the third commonest cause of death during these, usually healthy, years. What should be done by way of assessment, treatment, and prevention?

A working party of the Royal College of Psychiatrists has made sensible suggestions ${ }^{4}$ that include the opportunity for all children who deliberately injure themselves to get urgent psychiatric assessment and the offer of treatment: This opportunity is not, however, available eyerywhere. One of the obstacles to developing good services is a misplaced therapeutic nihilism which sees overdose as an impulsive response to minor stress, carried out by psychiatrically normal but emotionally self indulgent young people, who are using pills as a communication to others and are most unlikely to use psychiatric help. The view is dangerously incomplete. Several clinical studies of children and young adolescents who have deliberately poisoned themselves have reported a substantial subgroup with diagnosable psychiatric disorder. ${ }^{5-8}$ A comparison of schoolchildren who have taken overdoses with psychiatric outpatients matched for age, sex, social class, and place of residence has suggested that the former group are, if anything, more psychologically disturbed and more often meet operational criteria for depressive disorder. ${ }^{8}$ Those with evidence of longstanding psychological problems are particularly likely to poison themselves again, and in the highest risk group $50 \%$ attempt this within a year. ${ }^{9}$

In short, overdose is the presentation of a wide range of types and severity of psychological problems. Psychological assessment needs to formulate the immediate risk to life, the longer term outlook for emotional adjustment, the presence of other sorts of risk, and the opportunities for treatment.

\section{Risk to life}

Most drug overdoses are not very dangerous. Studies of children who have killed themselves ${ }^{10}$ or who have injured themselves seriously ${ }^{11}$ have found both dissimilarities and similarities to more minor self poisoning. Boys are more likely than girls to kill or damage themselves; but girls outnumber boys by 5-10 to 1 in overdosing groups. Fatal suicides more commonly involve intelligent, tall children who have planned for death effectively. On the other hand, both fatal and minor kinds of self injury tend to be triggered by the same sorts of crisis-rows over discipline, family argument, or parental illnesswhich may seem trivial to an unsympathetic observer.

The predictors of lethality are still too nonspecific to enable accurate discrimination. The best guide is probably the presence of a determined, mature attempt to end one's life. The extent of the danger is judged better by lethal intent and deliberate planning than by the physical damage actually caused. Much of the immediate physical hazard of an overdose depends simply upon what drugs happened to be in the bathroom cupboard at the time.

Kreitman's term 'parasuicide' 12 is sometimes used to make the distinction between those who have deliberately attempted suicide, but been unsuccessful, and those 'parasuicide' cases who have taken tablets to excess with a non-lethal motive, such as a communication to relatives and friends who may well have done the same themselves. In children, however, the distinction between attempted suicide and parasuicide is blurred. Motives are often mixed. A substantial minority-those most psychologically disturbed-say clearly that they wished to die. ${ }^{8}$ Even they, however, have often formed the intention rapidly, and abandon it later. Other children have indeed been desperate but perceive their motive as the escape from a difficult situation. In any case, parasuicide and attempted suicide are behaviours, not diagnoses, and both describe very heterogeneous groups of children.

\section{Emotional adjustment}

Many children who poison themselves are so disturbed that they would still need treatment even if they had never tried to hurt themselves. ${ }^{6} 8$ The 
clinical picture varies. Sometimes it is depressive, with prolonged misery and self blame and loss of sleep and appetite. ${ }^{8}$ Antisocial conduct is also common, ${ }^{13}$ though not necessarily any more frequent than in other young people who have been presented for psychological help through more orthodox routes. ${ }^{8}$ School refusal is common in the histories of both fatal suicides ${ }^{10}$ and self injurious behaviour. $^{6}$

Some children who have taken an overdose do not show any other psychiatric abnormality and may be reacting to stress in a way that is sanctioned by their subculture. This group is probably less likely to repeat the overdose in the short term. ${ }^{9}$ Whether they do so may depend upon the effects of the overdose upon other people. Their longer term outcome is not clear.

Otto's long term, controlled follow up study has emphasised the risks for later psychological adjustment. ${ }^{5}$ Nearly $5 \%$ had died by their own hand at the time of follow up-most of them within two years of the original act-and survivors showed high rates of convictions, marital problems, and emigration.

\section{Other risks}

Clinicians should be aware of the strong association between deliberate self injury and major breakdowns of family relationships. This has impressed many of the observers who have described their patients. ${ }^{14}$ Psychiatric disorder and alcohol abuse are often encountered in close relatives. ${ }^{10}{ }^{10}$ Lack of warmth and support at home are disproportionately common $^{8}$ and have amounted to neglect or physical abuse in many instances. ${ }^{18}$ Many of the children have run away from home at least once. ${ }^{8}$ Sexual abuse has also been described by suicidal girls, ${ }^{15}$ but it is hard to know how common it is. For all these reasons, an assessment of the wider family and social context is as important as judgements about the patient's mental state.

\section{Opportunities for treatment}

Because the problems giving rise to overdose are so various, no single scheme of treatment is likely to help everyone. Services need to be able to call upon several ways of working, and to experiment with new ways. On occasions crisis oriented, short term family therapy is called for-but sometimes this is impossible or pointless. Individual counselling for children can also help, especially for those who are most unhappy. Difficult care decisions may have to be taken as an emergency. Antidepressant medication is only rarely indicated, when an overtly and severely depressed child does not respond to attempts at psychological help. In those rare instances when drug treatment is given, drugs must of course be stored securely and administered by a responsible adult, if necessary through daily hospital attendance. Admission to an inpatient psychiatric unit should also be an uncommon treatment of late resort, either to try to prevent the actively suicidal from killing themselves or to enable a planned course of treatment that cannot be delivered in other ways. If lightly embarked on, hospital admission may encourage regression and the avoidance of stresses that ought to be mastered. Self help groups, cognitive therapy, and education about the effects of overdoses are experimental methods that deserve trial.

The absence of treatment trials is an embarrassment to the professions involved since the extension of effective treatment services will mean the provision or redeployment of resources, and the case will therefore have to be made with empirical support. When a new service is planned, the possibility of random allocation in the initial stages should be given serious consideration. Two separate kinds of trial are required: one, with immediate practical implications, is to evaluate existing 'packages' of treatment. The second is to compare specific therapies in particular subgroups: this latter type of trial might perhaps be deferred until research gives more precise indications of the mediators of outcome, and therefore more focussed targets for treatment.

The offer of treatment is much more than a ritual. Contrary to rumour, many children and families will reattend for psychological treatment. Fifty six per cent did so in one series of unselected consecutive cases. ${ }^{8}$ Those with more severe psychiatric disorders were the most likely to reattend. Good practice will ensure that the person making the assessment and offer of treatment will also carry it out, that treatment is offered in terms comprehensible to the child and family, and that there is little delay between assessment and treatment. Indeed, treatment starts with the very beginning of assessment and much can be done in the acute crisis of hospital admission.

It follows that good quality psychological management needs to call upon general hospital resources, and there remains a strong case for the admission of all those who have deliberately taken an overdose to a hospital ward. Discharge from the casualty department, with a later appointment to see an unnamed person in the psychiatric unit, is widespread but unlikely to help. It is also mistaken, because very many overdoses involve substances with psychotropic effects that can easily lead to the overlooking of abnormal mental states. The psycho- 
logical assessment cannot be done responsibly until the patient is no longer intoxicated, which may mean prolonging time spent in the ward, but is unavoidable.

Local circumstances differ, but there is much to be said for allowing one ward to develop a particular expertise. This could help to counteract the anger often expressed by health professionals to youngsters who are perceived as the agents rather than the victims of their own suffering. In adult medicine there is a move for physicians rather than psychiatrists to undertake the urgent mental assessment. ${ }^{16}$ For children and their families, however, the specifically medical aspects of management are limited: neither medication nor inpatient treatment are usually indicated. It makes better sense that the assessor should be the therapist too, and that members of child psychiatric teams (not necessarily medically trained) should accordingly be available to the wards at short notice.

The prevention of overdoses needs priority, and has not had it. The commonest source of the drugs or poisons used is the family store of medicines. Campaigns to stop the hoarding of dangerous substances should be tried and assessed. Indeed, secondary prevention after an overdose could well involve a home visit to reduce future access to danger.

Many of those taking overdoses $(50 \%$ in one series) ${ }^{7}$ have visited their family doctor in the weeks before their act. In theory, this might allow for early detection of a suicidal frame of mind. In practice, the decision to poison oneself, like other decisions made in childhood, is often taken and acted on precipitately. The provision of preventive counselling services should not be confined only to those who say they are suicidal. Development of services could therefore be through informal and easy access resources, such as school counsellors or advisors available by telephone.

If culturally determined attitudes make some children more likely to take overdoses, then educa- tion could, in principle, have a most important role. The very first step should be to understand the current attitudes of children and adolescents towards overdose as a response to life stress. Research in this subject should be commissioned now. It is likely to lead on to formulations of what needs to change.

\section{E TAYLOR Institute of Psychiatry, London SE5 8AF}

\section{References}

${ }^{1}$ Hawton K. Attempted suicide in children and adolescents. J Child Psychol Psychiatry 1982;23:497-503.

2 Hawton K, Goldacre M. Hospital admissions for adverse effects of medicinal agents (mainly self-poisoning) among adolescents in the Oxford region. Br J Psychiatry 1982;141:166-70.

${ }^{3}$ McClure GMG. Recent trends in suicide amongst the young. $\mathrm{Br}$ J Psychiatry 1984;144:134-8.

${ }^{4}$ Black M, Erulkar J, Kerfoot M, Meadow R, Baderman H. The management of parasuicide in young people under sixteen. Bulletin of the Royal College of Psychiatrists 1982;6:182-5.

5 Otto U. Suicidal acts by children and adolescents. Acta Psychiatr Scand 1972; Suppl 233.

${ }^{6}$ Lumsden Walker W. Intentional self-injury in schoolage children: a study of fifty cases. $J$ Adolesc 1980;3:217-28.

${ }^{7}$ Hawton K, O'Grady J, Osborn M, Cole D. Adolescents who take overdoses: their characteristics, problems and contacts with helping agencies. Br J Psychiatry 1982;140:118-23.

8 Taylor EA, Stansfeld SA. Children who poison themselves. I. A clinical comparison with psychiatric controls. II. Prediction of attendance for treatment. Br J Psychiatry 1984;145:127-35.

9 Hawton K, Osborn M, O'Grady J, Cole D. Classification of adolescents who take overdoses. Br J Psychiatry 1982;140: 124-31.

10 Shaffer D. Suicide in childhood and early adolescence. J Child Psychol Psychiatry 1974;15:275-91.

11 Kosky R. Childhood suicidal behaviour. J Child Psychol Psychiatry 1983;24:457-68.

12 Kreitman N. Parasuicide. London: Wiley, 1977.

13 Tuckman J, Connon HE. Attempted suicide in adolescents. Am J Psychiatry 1962;119:228-32.

14 Brooksbank DJ. Suicide and parasuicide in childhood and early adolescence. Br J Psychiatry 1985;146:459-63.

15 Anderson LS. Notes on linkage between the sexually abused child and the suicidal adolescent. $J$ Adolesc 1981;4:157-62.

16 Anonymous. 'Overdose-will psychiatrist please see?' Lancet 1981 ;i:195-6. 